\title{
SALIVARY SECRETION AND CHEWING: STIMULATORY EFFECTS FROM ARTIFICIAL AND NATURAL FOODS
}

\author{
SECREÇÃO SALIVAR E MASTIGAÇÃO: EFEITOS ESTIMULANTES DE \\ ALIMENTO ARTIFICIAL E NATURAL
}

Maria Beatriz Duarte GAVIÃO ${ }^{1}$, Andries Van der BILT ${ }^{2}$

\author{
1- Associate Professor, Department of Paediatric Dentistry, Dental School of Piracicaba, State University of Campinas (FOP/UNICAMP), \\ Piracicaba SP, Brazil. \\ 2- Department of Head and Neck, Oral Physiology Group, University Medical Center, Utrecht, The Netherlands. \\ Corresponding address: Maria Beatriz Duarte Gavião - Department of Pediatric Dentistry - Dental School of Piracicaba - University of \\ Campinas - Av. Limeira 901 - CEP 13414-018 - Piracicaba - SP - Brasil - Telephone: +55-19 34125368 - Telefax: +55-19 34125218 \\ e-mail: mbgaviao@fop.unicamp.br \\ Received: June 06, 2003 - Retturned for modification: August 06, 2003 - Accepted: August 19, 2003
}

\begin{abstract}
$7 \Gamma$

he aim of the present study was to determine the relationship between the flow rate of saliva and characteristics of the food. Therefore, we determined the rate of saliva secretion in 16 healthy subjects in rest and while chewing natural and artificial foods (toast with and without margarine, three sizes of breakfast cake, and Parafilm). We also determined the chewing rate, number of chewing cycles until swallowing, and time until swallowing. The physical characteristics of the foods were quantified from force-deformation experiments. The results showed that the average at which mechanical failure occurred (yield force) was 1.86 $\pm 0.24 \mathrm{~N}$ for the breakfast cake and $16.3 \pm 1.3 \mathrm{~N}$ for the melba toast. The flow rates obtained without stimulation and with Parafilm were significantly lower $(\mathrm{P}<0.001)$ than the flow rates obtained from chewing food. No differences in flow rate occurred between the natural foods. The flow rates of the saliva as obtained without stimulation, with Parafilm stimulation, and with chewing on the various foods were significantly correlated $(\mathrm{P}<0.05)$. There were no significant differences in chewing rate among the foods. The number of chewing cycles and the time until swallowing significantly depended on the type or volume of the food.
\end{abstract}

UNITERMS: Saliva; Flow Rate; Mastication; Food.

\section{RESUMO}

objetivo deste estudo foi determinar a relação entre o fluxo salivar e características de diferentes alimentos. Avaliou-se a taxa de secreção salivar em 16 indivíduos saudáveis, sem estimulação, na estimulação com Parafilm e na mastigação de alimentos naturais (torrada com e sem margarina e 3 volumes de bolo industrial). Determinou-se também a velocidade, o tempo de mastigação, o número de ciclos mastigatórios até o limiar da deglutição. As características físicas dos alimentos foram quantificadas através da experimentação força-deformação. Os resultados mostraram que a média em que a falha mecânica ocorreu foi 1,86 \pm 0,24 N para o bolo industrial e 16,3 \pm 1,3 $\mathrm{N}$ para a torrada. Os fluxos salivares obtidos sem estimulação e com a estimulação pelo Parafilm foram significativamente menores $(\mathrm{P}<0,001)$ que os fluxos salivares obtidos na mastigação dos alimentos naturais. Não houve diferença significativa no fluxo salivar entre os alimentos naturais. Os fluxos salivares obtidos sem estimulação, com estimulação pelo Parafilm e na mastigação dos vários alimentos foram significantemente correlacionados $(\mathrm{P}<0,05)$. Não houve diferença significativa na velocidade da mastigação entre os alimentos. O número de ciclos mastigatórios e o tempo de mastigação até o limiar da deglutição dependeram do tipo e do volume do alimento.

UNITERMOS: Saliva, Fluxo Salivar, Mastigação, Alimento.

\section{INTRODUCTION}

Saliva is implicated in a wide variety of physiological and biological processes that are crucial to the initial digestion in the upper parts of the gastrointestinal (GI) tract including lubrication, cleansing, enzymatic digestion and maintenance of dental and mucosal integrity ${ }^{16}$. Reduction of particle size, reduction of resistance against food deformation and the formation of a coherent bolus that can be swallowed are the main goals of the chewing process. Saliva moistens the fragmented food particles 
during chewing, so that the food can be swallowed ${ }^{17}$. Salivary glands and the saliva they produce also play a major role in the health of the oral cavity and the proximal portion of the gastrointestinal tract ${ }^{11}$.

The whole saliva is derived predominantly from three paired major salivary glands, i.e. the parotid, submandibular and sublingual glands (together accounting for about $90 \%$ of the fluid production) as well as from the minor salivary glands in the oral mucosa ${ }^{16}$. Under stimulated conditions parotid glands contribute approximately $25 \%$ of whole saliva, the submandibular/ sublingual glands about $67 \%$ and minor salivary glands about $8 \%{ }^{5,20}$. At high-stimulated flow rates, parotid saliva may constitute up to $49 \%$ of whole saliva ${ }^{21}$.

Many studies report on the flow rate of saliva in response to gustatory stimulation with acid ${ }^{25}$, to mechanical stimulation from chewing inert materials ${ }^{8,10}$, or to chewing natural foods ${ }^{10,15,18,24}$. The mean salivary flow rate while chewing rhubarb pie and rice was 70 and 43 per cent, respectively, of the maximum flow rate elicited by citric acid ${ }^{25}$. The salivary flow rate, while chewing food, is elicited by gustatory and mechanical stimulation and the gustatory stimulation of natural food in producing the flow of saliva appeared to be much more important than the mechanical stimulation from chewing ${ }^{24}$. Consistency and volume of the food will influence the flow rate of the saliva. The consistency of food can be quantified by the deformation of a food sample under mechanical force ${ }^{14}$.

The aim of the present study was to determine the relationship between the flow rate of saliva and the consistency and volume of the food. Therefore, we determined the rate of saliva secretion, while chewing various natural and artificial foods. Furthermore, we determined the number of chewing cycles and the time before the food was swallowed. The physical characteristics of the foods were quantified from force-deformation experiments.

\section{MATERIALSAND METHODS}

\section{Subjects}

Sixteen healthy subjects -8 males and 8 females aged from 16 to 60 years (mean age $35 \pm 13$ years) participated in the study. They all had a natural dentition at least up to the second molars and without evident defect of dental structures and periodontal conditions, and did not exhibit severe malocclusion (e.g. posterior cross-bite, anterior open-bite, poor or incomplete eruption of the canine teeth or extreme crowding of teeth), assessed by intraoral examination. The Ethics Committee of the University Medical Center Utrecht approved the protocol. Written informed consent was obtained from each subject after a full explanation of the experiment.

\section{Saliva collection}

The subjects were seated comfortably in an upright position, with back support up to midscapular level but without headrest. Salivary samples were collected under quiet circumstances in a laboratory. First, unstimulated saliva was obtained, so that a "baseline" flow rate could be determined ${ }^{3}$. Unstimulated saliva was collected over a period of $5 \mathrm{~min}$. Before collection, the mouth was emptied by an initial swallow. The examinator asked the subjects to spit out the produced saliva each 30 seconds. Stimulated saliva was obtained by chewing $5 \mathrm{~min}$. on a piece of tasteless paraffin (0.29 g; Parafilm "M" ${ }^{\circledR}$, American National $\mathrm{Can}^{\mathrm{TM}}$, Chicago, IL, USA). Again, the examinator asked the subject to spit out saliva each 30 seconds. The weight of saliva in grams was assumed to equal the milliliters of saliva secreted, because the specific density of saliva is close to $1.0^{18}$. Thus, secretion rates were obtained in $\mathrm{mL} / \mathrm{min}$, for the unstimulated and stimulated saliva. Next, saliva was obtained by chewing on several natural foods: toast (Melba toast; Buitoni, Italy, www.buitoni.com; $2.7 \mathrm{~g}, 7.9 \mathrm{~cm}^{3}$ ) without and with margarine (Linera-Unilever; the Netherlands, www.unilever.nl; $2.0 \mathrm{~g}$ ) and three portions of breakfast cake (Right, Peijnenburg, the Netherlands, www.right.nl), which were cut in rectangular blocks of $17 \times 18 \times 30 \mathrm{~mm}\left(9.2 \mathrm{~cm}^{3}, 5.6 \mathrm{~g}\right), 26 \times 18 \times 30 \mathrm{~mm}\left(14 \mathrm{~cm}^{3}, 8.6 \mathrm{~g}\right)$, and $37 \times 18 x 30 \mathrm{~mm}\left(20.0 \mathrm{~cm}^{3}, 13.2 \mathrm{~g}\right)$, respectively. These volumes will be further referred to as small, medium and large. Before the experiment, all foods were brought to room temperature $\left(20^{\circ} \mathrm{C}\right)$. Margarine was stored at $4{ }^{\circ} \mathrm{C}$. We assumed that the saliva produced equals the difference between the weight of the served food and the weight of chewed food that is collected when the test subjects are ready for swallowing ${ }^{24}$. The natural test foods were given to the subjects in a predetermined sequence. The subjects were asked to chew the food in their usual manner until they wanted to swallow. Instead of swallowing they spat out the food bolus into a pre-weighed container. Prior to the beginning of the experiments it was emphasized that all chewed material needed to be recovered. We used a probe to facilitate the removal of trapped particles. The subjects were also instructed to clean their mouths with tongue and cheeks while spitting into the preweighed containers. The tests were repeated two times with natural test foods. The volume of saliva was determined by subtracting the initial weight of the food from that of the food/ saliva mixture. For each food, salivary flow rate was calculated as the volume of saliva secreted, divided by the time the food was in the mouth $(\mathrm{mL} / \mathrm{min})$. Swallowing was not permitted during the test. It was allowed to sip water after each experiment. All samples were collected during the morning, since salivary flow rate shows a circadian rhythm².

\section{Chewing cycles}

Masticatory mandibular movements were recorded by an optoelectronic device (Northern Digital Optotrak ${ }^{\mathrm{TM}}$; www.ndigital.com) during the chewing of natural test foods, in order to identify individual chewing cycles. The device tracks the 3-dimensional position of small infrared light emitting diodes (LEDs), which were attached to the mandible and to the head. By comparing their positions we obtained the movement of the mandible with respect to the head. From the generated plots we determined the number of chewing cycles until the individuals were ready to swallow (swallowing threshold), as well as the average time of each chewing sequence. 


\section{Food characteristics}

The physical properties of the natural food samples were tested by crushing the food in a pneumatic bite simulator. This apparatus consisted of a probe, attached to a pneumatic cylinder. The probe had a conical cusp with a slope of 120 degrees $^{14}$. The position of the probe during crushing was monitored by a linear variable differential transformer and the velocity was $1 \mathrm{~mm} / \mathrm{s}$. Force-deformation curves were obtained by plotting the data points of the force as a function of the percentage deformation of the food samples. From these curves the forces and compression percentages were obtained, where mechanical failure occurred. Six samples of each food were measured.

\section{Statistical analysis}

Analysis of variance (ANOVA) was applied to test the null hypothesis that there would be no statistical difference between the results obtained for the various foods. Subsequently, post hoc tests (least significant difference multiple comparison test) were used for pair wise comparisons of the results. A Pearson correlation was calculated for the flow rates obtained for the various foods.

\section{RESULTS}

\section{Food characteristics}

The average at which mechanical failure occurred (yield force) was $1.86 \pm 0.24 \mathrm{~N}$ for the breakfast cake and $16.3 \pm 1.3 \mathrm{~N}$ for the Melba toast. The values for the relative deformation of the food samples at this yielding point were 30\% (cake) and 16\% (toast).

\section{Flow rates of saliva}

The average values for the flow rates of the saliva as obtained for the various foods are given in Table 1. One-way analysis of variance (ANOVA) on the saliva flow rates showed a significant effect for the kind of saliva stimulation $(\mathrm{P}<0.001)$. Post hoc analysis showed that the flow rates obtained without stimulation and with Parafilm were significantly lower $(\mathrm{P}<0.001)$ than the flow rates obtained from chewing food. No differences in flow rate occurred between the various foods.

The flow rates of the saliva as obtained without stimulation, with Parafilm stimulation, and with chewing on the various foods were significantly correlated(Table 2).

\section{Swallowing threshold}

The average duration of a chewing cycle, the number of chewing cycles until swallowing, and the time until swallowing for the various foods are given in Table 3. One-way analysis of variance (ANOVA) on the cycle duration showed that there were no significant differences in cycle duration for the various

TABLE 1- Saliva flow rate ( $\mathrm{mL} / \mathrm{min})$ in response to different foods; average and (standard deviation)

\begin{tabular}{cllllll}
\hline Unstimulated & Parafilm & toast & $\begin{array}{c}\text { toast } \\
\text { margarine }\end{array}$ & $\begin{array}{l}\text { cake } \\
\text { (small) }\end{array}$ & $\begin{array}{c}\text { cake } \\
\text { (medium) }\end{array}$ & $\begin{array}{l}\text { cake } \\
\text { (large) }\end{array}$ \\
\hline $0.53^{\mathrm{a}}$ & $1.40^{\mathrm{a}}$ & $8.64^{\mathrm{b}}$ & $7.74^{\mathrm{b}}$ & $7.97^{\mathrm{b}}$ & $7.32^{\mathrm{b}}$ & $7.42^{\mathrm{b}}$ \\
$(0.28)$ & $(0.67)$ & $(5.06)$ & $(4.97)$ & $(5.02)$ & $(3.97)$ & $(3.61)$ \\
\hline
\end{tabular}

Values with different superscript letters differ significantly $(P<0.01)$

TABLE 2- Matrix of Pearson correlations between saliva flow rates obtained with various ways of stimulation
1.
2.
3.
4.
5.
6.
7.

\section{Unstimulated}

2. Parafilm

3. Toast

4. Toast plus margarine

5. Cake (small)

6. Cake (medium)

7. Cake (large)

\section{$0.74^{\mathrm{b}}$}

$0.57^{\mathrm{a}}$

$0.72^{b}$

$0.50^{a}$

$0.71^{\mathrm{b}}$

$0.66^{\mathrm{b}}$

\section{$0.77^{c}$}

$0.71^{b}$

$0.69^{b}$

$0.63^{b}$

$0.66^{b}$ $0.74^{b}$

$0.87^{c}$

$0.66^{b}$

$0.69^{b}$ $0.81^{\mathrm{c}}$

$0.92^{c}$

$0.89^{c}$

${ }^{\text {a }} \mathrm{P}<0.05 \quad{ }^{\mathrm{b}} \mathrm{P}<0.01 \quad{ }^{\mathrm{c}} \mathrm{P}<0.001$ (two-sided tests) 
foods. The number of chewing cycles and the time until swallowing depended significantly on the type or volume of food that was chewed (ANOVA). The number of chewing cycles until swallowing the toast significantly decreased due to the margarine. Furthermore, the number of chewing cycles increased linearly with the volume of the cake.

\section{DISCUSSION}

We measured whole saliva rather than that of an individual gland, because whole saliva better represents the oral environment ${ }^{12}$, despite it may not be well mixed in the mouth. Dawes, Macpherson ${ }^{4}$ found that the rate of clearance of sucrose varies markedly at different sites within the mouth. Sas, Dawes ${ }^{19}$ considered that stimulated samples mostly contained significantly higher proportions of parotid saliva, but the distribution of the parotid saliva was still extremely variable. These facts are important considering that various areas of the mouth will be exposed to different fluid environments, which may have important implications for the site-specificity of several oral diseases. The major functions of the oral phase in response to a meal are the mechanical disruption of food into smaller particles by chewing and addition of saliva which aids taste, bolus formation for swallowing (water and mucin), and initiates digestion of starch (amylase) and lipids (lipase) ${ }^{13}$. In this way, with the aim to verify the amount of saliva during chewing foods, the whole saliva is readily measurable ${ }^{23}$, and it is believed to be a more practical and appropriate method when there is a generalized finding of reduced salivary flow ${ }^{3}$. Due to retention of food in the mouth and inadvertent swallowing, the salivary flow will be slightly underestimated ${ }^{18,24}$.

The flow rate of unstimulated saliva was $0.53 \mathrm{~mL} / \mathrm{min}$, value slightly higher than found by Watanabe, Dawes ${ }^{24}, 0.4 \mathrm{~mL} / \mathrm{min}$, and unpublished observations, cited by Engelen, et al. ${ }^{6}, 0,4 \mathrm{~mL} /$ min. Mechanical stimulation, obtained from chewing on an inert and tasteless material (Parafilm) increased the flow rate up to 1.40 $\mathrm{mL} / \mathrm{min}$. This finding is in accordance with Pedersen, et al. ${ }^{16}$ who considered that the response to chewing paraffin is normally a three- or fivefold increase in the salivary flow rate compared with the unstimulated level. Nevertheless, this value is significantly lower than those obtained while chewing on natural foods (7.32 - $8.64 \mathrm{~mL} / \mathrm{min}$; Table 1). Parafilm is an inert and tasteless material, so it does not cause gustatory secretory stimulation. The effect of gustatory stimulation of foods is much more important than the mechanical stimulation from chewing for the saliva flow rate ${ }^{24}$, so this may explain the lower flow rate when chewing on Parafilm. Losso, et al. ${ }^{9}$ offer the conjecture that both stimulations are equally important, as the majority of the foods that we consume are both chewable and flavorsome. Furthermore, the Parafilm was chewed for a longer time ( $5 \mathrm{~min}$ ) than the natural foods ( 30 s or less; Table 3). This may lead to lower flow rates as there is evidence of a reduced flow rate with prolonged chewing ${ }^{1}$.

The unstimulated and stimulated saliva flow rates we found (Table 1) were similar to the flow rates reported previously ${ }^{8,24,25}$. Our flow rates elicited in response to chewing natural foods (Table 1) were slightly larger than the flow rates measured in previous studies. Amean salivary flow rate of $2.79 \pm 0.22 \mathrm{~mL} / \mathrm{min}$ was found in 34 subjects in response to a meal of steak, frenchfried potatoes and water ${ }^{18}$. Mean salivary flow rates in response to chewing on several natural foods ranged from 3.15 to $4.94 \mathrm{~mL} /$ $\min ^{25}$, whereas flow rates in response to eating cheese ranged between about 1.8 and $6.9 \mathrm{~mL} / \mathrm{min}^{22}$. No significant differences in flow rate exist among the various natural foods that we measured (Table 1), which is in agreement with previous results from Watanabe, Dawes ${ }^{25}$. Guinard, et al. ${ }^{7}$ found an increase of 1,5- to 8-fold compared to baseline saliva rates, using solid, semisolid foods and beverages, and the flow rate were from parotid gland. They confirmed a disproportional increase stimulated parotid flow with mechanical stimulation.

Significant correlations exist among the unstimulated flow rate, the stimulated flow rate, and the flow rates elicited by the natural foods (Table 2). Thus, determining the saliva flow rate from either unstimulated chewing or chewing on Parafilm is as good a method for obtaining an indication of the salivary flow as determining the flow rate from natural foods. The Parafilm method

TABLE 3- Average duration of a chewing cycle, number of chewing cycles until swallowing, and time until swallowing for the various foods; average and (standard deviation)

\begin{tabular}{|c|c|c|c|c|c|}
\hline & toast & $\begin{array}{c}\text { toast } \\
\text { margarine }\end{array}$ & $\begin{array}{l}\text { cake } \\
\text { (small) }\end{array}$ & $\begin{array}{c}\text { cake } \\
\text { (medium) }\end{array}$ & $\begin{array}{l}\text { cake } \\
\text { (large) }\end{array}$ \\
\hline Cycle duration (s) & $\begin{array}{l}0.64^{a} \\
(0.08)\end{array}$ & $\begin{array}{l}0.64^{a} \\
(0.09)\end{array}$ & $\begin{array}{l}0.61^{a} \\
(0.08)\end{array}$ & $\begin{array}{l}0.62^{a} \\
(0.07)\end{array}$ & $\begin{array}{l}0.67^{a} \\
(0.10)\end{array}$ \\
\hline Number of cycles & $\begin{array}{l}37.6^{a} \\
(9.9)\end{array}$ & $\begin{array}{l}32.4^{b} \\
(7.2)\end{array}$ & $\begin{array}{l}28.4^{c} \\
(7.3)\end{array}$ & $\begin{array}{l}36.9^{a} \\
(9.8)\end{array}$ & $\begin{array}{l}46.4^{d} \\
(10.5)\end{array}$ \\
\hline Chewing time (s) & $\begin{array}{l}23.8^{a} \\
(5.8)\end{array}$ & $\begin{array}{l}20.5^{b} \\
(4.5)\end{array}$ & $\begin{array}{l}17.4^{c} \\
(5.2)\end{array}$ & $\begin{array}{l}23.0^{a} \\
(6.5)\end{array}$ & $\begin{array}{l}30.7^{\mathrm{d}} \\
(7.2)\end{array}$ \\
\hline
\end{tabular}


may then be preferred, because it is the easiest and cleanest way of obtaining an adequate amount of saliva.

We observed no significant differences among the cycle durations while chewing on the various natural foods (Table 3). The average number of chewing cycles needed before swallowing toast significantly decreased when the toast had $2 \mathrm{~g}$ of margarine on it. Apparently, the margarine lubricates the food bolus, making it easier to swallow. The average number of chewing cycles until swallowing increased for larger volumes of cake (Table 3). More saliva and thus more time were needed to form a swallowable food bolus. The swallowing thresholds for toast and the medium volume of cake did not differ (Table 3), although the volumes of these foods differed over a factor of 3. Apparently, chewing the toast, that has a 10 times larger yield force than cake, took much more chewing effort than chewing cake and the toast, as solid and dry food, required accurate chewing movements before to swallow, agreeing with Guinard et al. ${ }^{7}$ who attributed to the mechanical stimulation the higher flow rates in relation to chemical stimulation.

\section{ACKNOWLEDGEMENTS}

This work was supported by the University Medical Center Utrecht, the Netherlands Institute for Dental Sciences, the University of Campinas, and the State of São Paulo Research Foundation(FAPESP). We are grateful to Dr. L. Engelen for critical reading of the manuscript.

\section{REFERENCES}

1- Brudevold F, Kashket S, Kent RL. The effect of sucrose and fat in cookies on salivation and oral retention in humans. J Dent Res 1990; 69:1278-82.

2- Dawes C. Circadian rhythms in human salivary flow rate and composition. J Physiol 1972; 220:529-45.

3- Dawes C. Physiological factors affecting salivary flow rate, oral sugar clearance, and the sensation of dry mouth in man. J Dent Res 1987; 66:648-53.

4- Dawes C, Macpherson LMD. The distribution of saliva and sucrose around the mouth during use of chewing gum and the implication of site-specificity of caries and calculus deposition. J Dent Res 1993; 72: 852-7.

5- Dawes C, Wood CM. The contribution of oral minor mucous and gland secretions to the volume of whole saliva in man. Arch Oral Biol 1973; 18:337-42.

6- Engelen L, de Wijk RA, Prinz JF, van der BILT A, Bosman F. The relation between saliva flow after different stimulations and the perception of flavor and texture attributes in custard desserts. Physiol Behav 2003; 78:165-9.

7-Guinard J-X, Zoumas-Morse C, Walchak C. Relation between parotid saliva flow and composition and perception of gustatory and trigeminal stimuli in foods. Physiol Behav 1998; 63:109-18.
8- Heintze U, Birkhed D, Bjorn H. Secretion rate and buffer effect of resting and stimulated whole saliva as a function of age and sex. Swed Dent J 1983; 7:227-38.

9- Losso EM, Singer JM, Nicolau J. Effect of gustatory stimulation on flow rate and protein content of human parotid saliva according to the side of preferential mastication. Arch Oral Biol 1997; 42: 83-7.

10- Mackie DA, Pangborn RM. Mastication and its influence on human salivary flow and alpha-amylase secretion. Physiol Behav 1990; 47:5935 .

11- Mandel ID. The functions of saliva. J Dent Res 1987; 66:623-7.

12- Mulligan R, Navazesh M, Wood GJ. A pilot study comparing three salivary collection methods in an adult population with salivary gland hypofunction. Spec Care Dentist 1995; 15:154-8.

13- Nauntofte B, Jensen JL. Salivary secretion. In: Yamada T, Alpers DH, Laine L, Owyang C, Powell DW, editors. Textbook of Gastroenterology. Philadelphia: Lippencott Williams, Wilkins; 1999. p. 263-78.

14- Olthoff LW, van der Bilt A, de Boer A, Bosman F. Comparison of force-deformation characteristics of artificial and several natural foods for chewing experiments. J Texture Stud 1986; 17:275-89.

15- Pangborn RM, Lundgren B. Salivary secretion in response to mastication of crisp bread. J Texture Stud 1977; 8:463-72.

16- Pedersen AM, Bardow A, Beier Jensen S, Nauntofte B. Saliva and gastrointestinal functions of taste, mastication, swallowing and digestion. Oral Dis 2002; 8: 117-29.

17- Prinz JF, Lucas PW. Swallow thresholds in human mastication. Arch Oral Biol 1995; 40:401-3.

18- Richardson CT, Feldman M. Salivary response to food in humans and its effect on gastric acid secretion. Am J Physiol 1986; 250:G85G91.

19- Sas R, Dawes C. The intra-oral distribution of unstimulated and chewing-gum-stimulated parotid saliva. Arch Oral Biol 1997; 42: 46974.

20- Scheyer LH. Source of resting total mixed saliva of man. J Appl Physiol 1956; 9: 79-81.

21-Shannon IL. Parotid flow rate as related whole saliva volume. Arch Oral Biol 1962; 7:391-394.

22- Silva MF, Jenkins GN, Burgess RC, Sandham HJ. Effects of cheese on experimental caries in human subjects. Caries Res 1986; 20: 263-9.

23- Sreebny LM. Recognition and treatment of salivary induced conditions. Int Dent J 1989; 39:197-204.

24- Watanabe S, Dawes C. A comparison of the effects of tasting and chewing foods on the flow rate of whole saliva in man. Arch Oral Biol 1988a; 33: 761-4.

25- Watanabe S, Dawes C. The effects of different foods and concentrations of citric acid on the flow rate of whole saliva in man. Arch Oral Biol 1988b; 33:1-5. 